\title{
BMJ Open Effect of prenotification on the response rate of a postal survey of emergency physicians: a randomised, controlled, assessor-blind trial
}

\author{
Michael Hickey (D) ,1,2 Lauralyn Mclntyre, ${ }^{2,3}$ Monica Taljaard (D) ,2 \\ Kasim Abdulaziz, ${ }^{2,4}$ Krishan Yadav, ${ }^{1,2}$ Carly Hickey, ${ }^{5}$ Jeffrey J Perry ${ }^{1,2}$
}

To cite: Hickey M, Mclntyre L, Taljaard M, et al. Effect of prenotification on the response rate of a postal survey of emergency physicians: a randomised, controlled, assessor-blind trial. BMJ Open 2021;11:e052843. doi:10.1136/ bmjopen-2021-052843

- Prepublication history and additional supplemental material for this paper are available online. To view these files, please visit the journal online (http://dx.doi.org/10.1136/ bmjopen-2021-052843).

Received 30 April 2021 Accepted 10 September 2021

Check for updates

(C) Author(s) (or their employer(s)) 2021. Re-use permitted under CC BY-NC. No commercial re-use. See rights and permissions. Published by BMJ.

${ }^{1}$ Department of Emergency Medicine, University of Ottawa, Ottawa, Ontario, Canada ${ }^{2}$ Clinical Epidemiology Program, Ottawa Hospital Research Institute, Ottawa, Ontario, Canada

${ }^{3}$ Department of Medicine, University of Ottawa, Ottawa, Ontario, Canada

${ }^{4}$ Department of Epidemiology and Community Medicine, University of Ottawa, Ottawa, Ontario, Canada

${ }^{5}$ Intensive Care Unit, Queensway Carleton Hospital, Ottawa, Ontario, Canada

Correspondence to

Dr Michael Hickey;

michael.hickey@unityhealth.to

\section{ABSTRACT}

Objectives Response rates to physician surveys are typically low. The objective of this study was to determine the effect of a prenotification letter on the response rate of a postal survey of emergency physicians.

Design This was a substudy of a national, crosssectional postal survey sent to emergency physicians in Canada. We randomised participants to either receive a postal prenotification letter prior to the survey, or to no prenotification letter.

Participants A random sample of 500 emergency physicians in Canada. Participants were selected from the Canadian Medical Directory, a national medical directory which lists more than $99 \%$ of practising physicians in Canada.

Interventions Using computer-generated randomisation, physicians were randomised in a concealed fashion to receive a prenotification letter approximately 1 week prior to the survey, or to not receive a prenotification letter. All physicians received an unconditional incentive of a $\$ 3$ coffee card with the survey instrument. In both groups, non-respondents were sent reminder surveys approximately every 14 days and a special contact using Xpresspost during the final contact attempt.

Outcome The primary outcome was the survey response rate.

Results 201 of 447 eligible physicians returned the survey (45.0\%). Of 231 eligible physicians contacted in the prenotification group, $80(34.6 \%)$ returned the survey and among 237 eligible physicians contacted in the noprenotification group, $121(51.1 \%)$ returned the survey (absolute difference in proportions $16.5 \%, 95 \% \mathrm{Cl} 2.5$ to $30.5, p=0.01$ ).

Conclusion Inclusion of a prenotification letter resulted in a lower response rate in this postal survey of emergency physicians. Given the added costs, time and effort required to send a prenotification letter, this study suggests that it may be more effective to omit the prenotification letter in physician postal surveys.

\section{INTRODUCTION}

Physician surveys are an important method for obtaining information in research studies that aim to ultimately improve the delivery of healthcare. For a number of proposed

\section{STRENGTHS AND LIMITATIONS OF THIS STUDY}

$\Rightarrow$ The survey instrument that this study was based on was robustly designed using cognitive interviews and pilot testing.

$\Rightarrow$ The participants in the survey were randomly selected from the most comprehensive database of Canadian physicians.

$\Rightarrow$ The results may not be generalisable to all physician populations.

reasons, adequate response rates remain difficult to achieve. ${ }^{1}$ Surveys of physicians typically have a response rate as low as $10 \%$ points less than that of the general population. ${ }^{2}$ Over the past decade, much emphasis in the literature has been placed on identifying strategies to improve response rates among physicians and other health providers. ${ }^{13-6}$ Several strategies aimed at increasing physician survey response rates have been employed with variable success, including but not limited to unconditional financial incentives, designbased interventions, special envelope types and method of delivery. ${ }^{6-10}$ Dillman's tailored design method is a well-established technique that focuses on all aspects of internet and postal surveys with a goal that the respondent will believe that the expected benefits of responding outweigh the costs, and therefore increasing the likelihood of response. ${ }^{11}$ Practically, examples include using a clear and easily comprehendible survey instrument, implementing repeated contacts including a prenotification letter, using a postage-paid, addressed return envelope, personalisation of correspondence and an unconditional financial incentive. ${ }^{11}$ Postal surveys of physicians have had more favourable response rates than other modes, such as internet-based approaches. ${ }^{6} 912$ Prenotification has previously been reported to increase the response 
rate of physician surveys. Shiono and Klebanoff ${ }^{13}$ tested the effect of the response rate on a postal survey of resident physicians (ie, doctors in training) and reported that the prenotification letter was not associated with an increase in response rate, and may have had a deleterious effect. In an electronic web-based survey of 3550 general internists in the USA, a postal prenotification letter increased the response rate from $3.0 \%$ to $6.2 \%{ }^{14}$ Additionally, a Cochrane systematic review from 2009 also reported that prenotification increased response in health related surveys, some of which included physician surveys. ${ }^{15}$ To the contrary, Gattellari et $a l^{16}$ reported that the addition of a mailed or faxed prenotification letter to family physicians did not result in a change in the response rate. In addition, Xie and Ho reported that prenotification did not increase the response rate of a survey of nurses in Hong Kong. ${ }^{17}$ Interestingly, prenotification by letter has been previously shown to increase responses in the social sciences literature ${ }^{18}$ and as such, it is of interest to investigate whether or not this translates into surveys of physicians. This certainly may not be the case, since the literature examining the effect of prenotification on physician surveys is quite mixed. The motivation to perform the current study is threefold. First, as described above, the literature reports mixed results with regards to prenotification and physician-survey response rates, and so equipoise remains. Second, most of the studies that have examined this were reported in an era where the postal route was still the mainstay of communication, unlike the present day. Finally, the effect of prenotification has been studied in some other populations, but not specifically emergency physicians. Since postal surveys are now less frequently encountered, the effect of prenotification on a present-day postal survey is of considerable interest. Given that prenotification adds time and cost to the development and administration of a survey, whether it can be eliminated from future surveys is important to examine. The objective of the current study is to determine the effect of prenotification on the response rate of a postal survey of emergency physicians in Canada. Specifically, the present study tests the effect of a typed, hand-signed postal letter sent to emergency physicians via mail prior to receiving the survey.

\section{METHODS}

\section{Study design and participants}

This was an a priori substudy of a national, selfadministered postal survey of Canadian emergency physicians. The purpose of the survey was to examine emergency physicians' attitudes towards and acceptability of an intervention of promoting organ donation registration of patients and visitors while they await medical care in the emergency department. The current substudy was then designed to assess the effect of survey prenotification on the survey response rate. To be eligible for the study, physicians needed to be currently practising emergency medicine in Canada. The first contact occurred on
12 December 2019, with a reminder letter and additional copy of the survey every 2 weeks for a total of 6 weeks. The final contact was mailed on 24 February 2020. We delayed the second contact by 1 week due to the date falling within the Christmas/New Year holiday season. While the study was conducted based on a protocol written a priori (see online supplemental material), it was not registered.

\section{Patient and public involvement}

Neither patients nor the public were formally involved in the planning of the study.

\section{Outcome measure}

Our primary outcome was the survey response rate, which was determined a priori.

\section{Survey development}

The survey instrument was designed using rigorous methodology and with reference to Dillman's tailored design technique. ${ }^{11}$ We conducted key-informant interviews with 12 experts with advanced knowledge in organ donation and survey methodology which included critical care and emergency physicians, nurses and research methodologists. The instrument was then drafted in English and translated into French based on physician language preference according to the Canadian Medical Directory. We then conducted 10 cognitive interviews in both languages with five attending and five resident emergency physicians whereby participants were directly observed selfadministering the survey. The questions were read aloud, and participants were encouraged to express thoughts, comments or concerns while they completed the survey. In doing so, we were able to flag any potential problems with regards to the content, flow, language and grammar of the survey, which took about $15 \mathrm{~min}$ to complete. After minor adjustments, we conducted pilot surveys of 20 randomly selected emergency physicians from our sample in an attempt to identify any issues with the postal procedure or completion of the survey. The final survey instrument consisted of 24 questions divided into four sections, double-sided on two sheets of paper: demographic and practice information, attitudes regarding organ donation, acceptability of using the emergency department to promote organ donation and registration and related perceived facilitators and barriers (online supplemental file 1). No modifications were required following the pilot phase.

\section{Sample selection}

From our sampling frame of 2955 emergency physicians identified in the Canadian Medical Directory, which claims to be Canada's most comprehensive directory of medical professionals, we used computer-generated random numbers select a sample of physicians with emergency medicine listed as a credential for the survey. The sample size necessary for the survey was calculated based on a key question around participants support for organ donation registration in the emergency department. It was based on a variance of 0.25 with $95 \%$ CI and a margin 
Table 1 Physician respondent demographics for prenotification group $(n=80)$ and no prenotification group $(n=121)$

\begin{tabular}{|c|c|c|}
\hline Characteristic & $\begin{array}{l}\text { Prenotification } \\
\text { group }\end{array}$ & $\begin{array}{l}\text { No prenotification } \\
\text { group }\end{array}$ \\
\hline & n (\%) & n (\%) \\
\hline \multicolumn{3}{|l|}{ Sex } \\
\hline Male & $49(61.3)$ & 77 (63.6) \\
\hline Female & $31(38.8)$ & $44(36.4)$ \\
\hline \multicolumn{3}{|l|}{ Language } \\
\hline English & 65 (81.3) & $94(77.7)$ \\
\hline French & $15(18.7)$ & 27 (22.3) \\
\hline \multicolumn{3}{|l|}{ Age } \\
\hline$<35$ & $6(7.5)$ & $8(6.6)$ \\
\hline $35-44$ & $27(33.8)$ & $40(33.1)$ \\
\hline $45-54$ & $20(25.0)$ & 39 (32.2) \\
\hline $55-64$ & 17 (21.3) & $22(18.2)$ \\
\hline$>65$ & $5(6.3)$ & $10(8.3)$ \\
\hline Unanswered & $5(6.3)$ & $2(1.7)$ \\
\hline \multicolumn{3}{|l|}{ Years in practice } \\
\hline$<5$ & $31(38.8)$ & $40(33.1)$ \\
\hline $5-10$ & $30(37.5)$ & $44(36.4)$ \\
\hline $11-20$ & $13(16.3)$ & $26(21.5)$ \\
\hline$>20$ & $6(7.5)$ & $11(9.1)$ \\
\hline \multicolumn{3}{|l|}{ Religious affiliation } \\
\hline Christian & $42(52.5)$ & $61(50.4)$ \\
\hline None & $26(32.5)$ & $41(33.9)$ \\
\hline Muslim & $2(2.5)$ & $5(4.1)$ \\
\hline Other & $5(6.3)$ & $4(3.3)$ \\
\hline Buddhist & $2(2.5)$ & $3(2.5)$ \\
\hline Jewish & $1(1.3)$ & $4(3.3)$ \\
\hline Sikh & $0(0.0)$ & $3(2.5)$ \\
\hline Hindu & $1(1.3)$ & $0(0.0)$ \\
\hline Unanswered & $1(1.3)$ & $0(0.0)$ \\
\hline \multicolumn{3}{|l|}{ Location of practice } \\
\hline Ontario & $35(43.8)$ & $48(39.7)$ \\
\hline Quebec & 17 (21.3) & $29(24.0)$ \\
\hline British Columbia & $15(18.8)$ & $20(16.5)$ \\
\hline Alberta & $5(6.3)$ & $12(9.9)$ \\
\hline Manitoba & $1(1.3)$ & $3(2.5)$ \\
\hline $\begin{array}{l}\text { Newfoundland } \\
\text { and Labrador }\end{array}$ & $3(3.8)$ & $1(0.8)$ \\
\hline New Brunswick & $2(2.5)$ & $1(0.8)$ \\
\hline Nova Scotia & $1(1.3)$ & $2(1.7)$ \\
\hline Saskatchewan & $0(0.0)$ & $3(2.5)$ \\
\hline $\begin{array}{l}\text { Prince Edward } \\
\text { Island }\end{array}$ & $1(1.3)$ & $1(0.8)$ \\
\hline Unanswered & $0(0.0)$ & $1(0.8)$ \\
\hline
\end{tabular}

of error of 0.07. This resulted in 196 subjects. Based on an expected response rate of $40 \%-50 \%$ from previous studies that surveyed the same population, ${ }^{6}{ }^{12}$ we chose to randomly sample 500 physicians in order to achieve this goal. Following this, an independent set of computergenerated random numbers were used to assign half of the physicians to receive a prenotification letter, and the other half to controls (no prenotification) using a 50/50 allocation ratio. Randomisation was performed by a member of the study team who was not involved in data collection or analysis. Based on language preference, 77 of the total number of surveys were sent in French. From the sample of 500, we selected 20 physicians located near our geographical area to receive the survey as pilot subjects (to minimise postal travel time) with intention to test the survey instrument and the postal procedure of distribution and return. Since the survey instrument did not require alteration once pilot participant responses were analysed, these pilot surveys were included in the data analysis.

\section{Intervention}

Prenotification letters were hand-signed by the principal investigator and sent to half the randomly selected participants approximately 1 week prior to the first questionnaire mailout. The principal investigator was blinded to the demographic information of the participants. The letter outlined the purpose of the study and emphasised the importance of the physicians' contribution (online supplemental file 2). The other half did not receive prenotification, and therefore were considered controls. All physicians in both groups received a \$3 Tim Hortons coffee card which was included with the first survey as an unconditional incentive.

\section{Survey administration}

Approximately 1 week following the prenotification letter that half the participants received, our survey instrument, an introductory letter, a \$3 Tim Hortons coffee card (national coffee shop) and an addressed, postagepaid return envelope was sent to all physicians, in either English or French languages, based on physician preference stated in the Canadian Medical Directory. A reminder letter and additional copy of the survey were sent to non-respondents approximately every 2 weeks for a total of 6 weeks. The final reminder was delivered via courier (Xpresspost), a trackable, larger special envelope delivered nationally within two business days.

\section{Data analysis}

Using blinded outcome assessment, physician responses were analysed using descriptive statistics. Although the response to the first item in the survey determined respondent eligibility (a binary question indicating current practice of emergency medicine in Canada), we included all physicians who did return the survey in the overall calculation of the response rate. However, given that some respondents were ineligible to complete the 


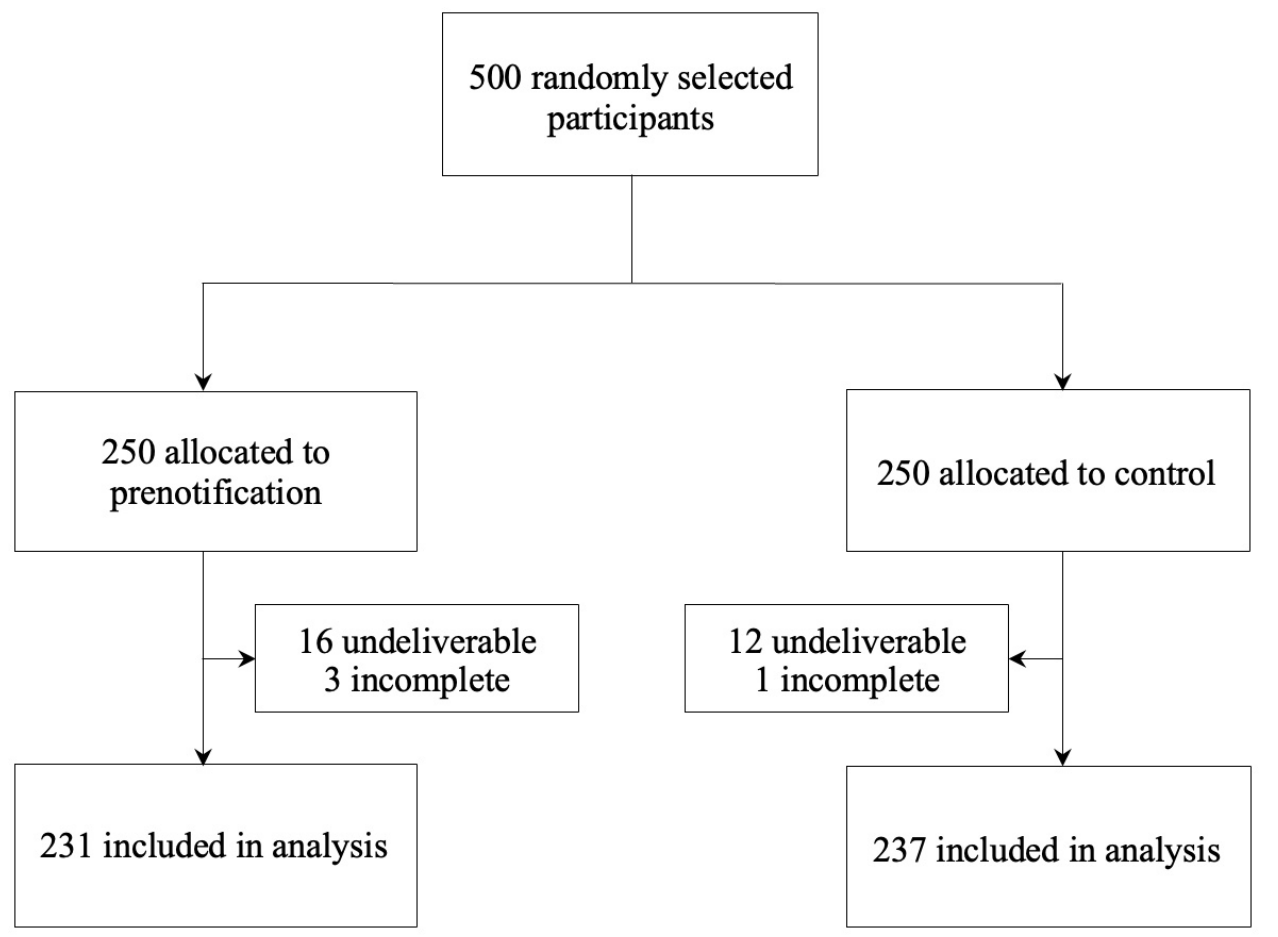

Figure 1 Participant flow diagram.

subsequent items in the questionnaire (because they reported to not be currently practising emergency medicine in Canada), they were not included in further data analysis other than the response rate calculation. The randomised groups were compared using a $\chi^{2}$ tests. The response rate was calculated in each group and compared

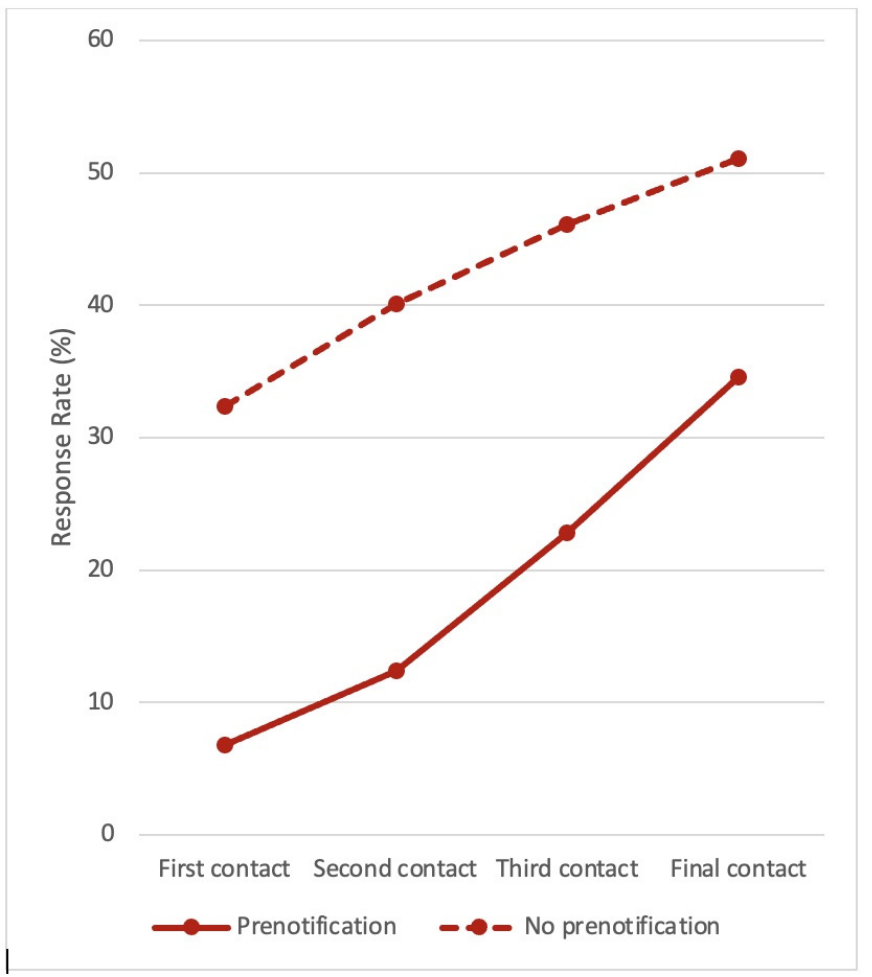

Figure 2 Response rates for prenotification and nonprenotification groups by contact number. using absolute difference in proportions with 95\% CI. Cumulative response rates were also reported after each reminder letter. We also assessed for non-response bias using $\chi^{2}$ tests based on language preference and geographic region of Canada. Data were analysed using SAS V.9.2 (SAS Institute).

\section{RESULTS}

\section{Respondents}

Demographic information for the respondents is shown in table 1 . The majority of respondents were men $(62.7 \%)$, $33.3 \%$ were in the 35-44year age range and $72.1 \%$ have been in practice for 10 years or less. The majority of respondents practise in the most populous Canadian provinces: Ontario $(41.3 \%)$, Quebec $(22.9 \%)$ and British Columbia $(17.4 \%)$.

\section{Response rate}

Of 500 physicians contacted (which included the 20 pilot participants), 26 were undeliverable and 7 surveys were returned incomplete (see figure 1). Twenty-seven physicians indicated that they were no longer practising emergency medicine in Canada and were therefore considered ineligible to complete the survey. Of 474 physicians to whom a survey was delivered, $228(48.1 \%)$ returned the survey and after assessment for eligibility, $45.0 \%$ of the total eligible respondents were included in the data analysis of the main survey (reported separately); $3.1 \%$ of participants were not included in the data analysis because they indicated that they were not presently practising emergency medicine in Canada. Of 231 physicians contacted in the prenotification group, 80 
Table 2 Assessment of non-response bias

\begin{tabular}{|c|c|c|c|}
\hline Characteristic & Respondents, n (\%) & Non-respondents, n (\%) & $P$ value \\
\hline Geographic region & & & 0.45 \\
\hline Western Canada* & 59 (29.5) & 76 (30.9) & \\
\hline Ontario & $83(41.5)$ & $99(40.2)$ & \\
\hline Quebec & $46(23.0)$ & $53(21.5)$ & \\
\hline Eastern Canada† & $12(6.0)$ & $18(7.3)$ & \\
\hline Survey language & & & 0.22 \\
\hline English & $159(83.1)$ & 209 (85.0) & \\
\hline French & $42(16.9)$ & $37(15.0)$ & \\
\hline
\end{tabular}

*Alberta, British Columbia, Manitoba, Saskatchewan.

†New Brunswick, Nova Scotia, Newfoundland, Prince Edward Island.

$(34.6 \%)$ returned the survey and among 237 physicians contacted in the no-prenotification group, 121 (51.1\%) returned the survey (absolute difference in proportions $16.5 \%, 95 \%$ CI 2.5 to $30.5, \mathrm{p}=0.01$; OR $0.51,95 \%$ CI 0.35 to $0.74, \mathrm{p}=0.0004)$. The largest difference in response rate between prenotification and no prenotification was observed after the first contact ( $6.8 \%$ vs $32.4 \%$; figure 2$)$. Small increases in response rate were observed with each contact in both groups.

We performed an assessment of potential non-response bias among known characteristics of non-responders using $\chi^{2}$ test on language preference and region (table 2 ). There were no differences detected among responders and non-responders with respect to language preference $(p=0.22)$ or region in Canada $(p=0.45)$.

\section{DISCUSSION}

We found that sending a prenotification letter prior to a postal survey of emergency physicians in Canada resulted in a significantly lower response rate. Prior literature regarding prenotification in physician surveys have reported mixed results. To optimise our response rate for this study, we decided to include an unconditional incentive to all participants which was received along with the first survey. This method was based on a previous study that examined the effect of including an unconditional incentive in a postal survey of emergency physicians in Canada. ${ }^{6}$ The authors observed a significant increase in response rates in those who received an incentive. We observed that those who did not receive a prenotification letter had a much higher response rate after the first contact. The incentive was not mentioned in the prenotification letter and it is unclear if this had an effect on the subsequent actions of physicians. It is possible that those who received prenotification and were not interested in taking part in the study did not open the first contact package containing the incentive, and therefore were unaware of it, leading to a lower response rate than the no prenotification group after the first contact.

Our survey instrument for this study was designed using robust methodology and refined after performing cognitive interviews and pilot testing. As an a priori substudy of a larger study regarding physicians' attitudes and acceptability of an intervention promoting organ donation registration in the emergency department, we were able to test the utility of including a prenotification letter in future surveys involving emergency physicians. The prenotification letter for postal surveys adds cost and additional time required to complete the study, as well as additional time and effort for participants to review it. The estimated cost of each prenotification letter (including stationery and postage was approximately $\$ 1.29 \mathrm{CAD}$ which for large surveys), can be costly. Our study suggests that this step may not be necessary in physician postal surveys. The authors hypothesise that the reason for a lower response rate for the prenotification group may be twofold. It could be due to a displeasure that an overextended physician might experience during an additional contact to inform of a survey that has not yet begun. Another possibility may be that once the physician knows they will receive a survey about a certain subject, they may spend additional time considering the subject matter and decide against participating. An additional strength of our study is regarding the source we selected our sample from. The Canadian Medical Directory is a national medical directory which claims to list 91000 practising physicians in Canada. It is likely that future physician postal surveys will use this resource and therefore, we feel that the results of our study are generalisable for future surveys of emergency physicians. There also exists no other comprehensive database that contains postal addresses for Canadian emergency physicians.

Our study does have some weaknesses. The difference in effect size of the response rates was much larger than anticipated and demonstrated statistical significance. We did not calculate an a priori sample size for the randomised trial embedded within the larger survey study. However, with an available sample size of 250 physicians per arm, there would be an $80 \%$ power to detect an absolute difference of $13 \%$ assuming a response rate of $50 \%$ in one arm. 
As described, several physicians were not reachable at the noted address, and several others reported to having ceased practice in emergency medicine. Also, our data regarding the effect of prenotification may not apply to electronic or internet-based surveys, which are more commonly reported in the literature and however often have very low response rates. Finally, given that this study was focused on a specific area in organ donation, the results may not be generalisable to other subject areas or physician populations.

Future research could assess the effect of electronic prenotification in electronic or internet-based surveys, as well as in surveys sent to physicians in other specialties and based in various other realms of subject matter. Additionally, it would be helpful to undertake a follow-up study using a mixed-methods approach to further understand the results by contacting non-respondents in both arms of our study.

\section{CONCLUSION}

Inclusion of a prenotification letter resulted in a lower response rate in this postal survey of emergency physicians. Given the added costs, time and effort required to send a prenotification letter, this study suggests that it is more effective to omit the prenotification letter in future physician surveys.

\section{Twitter Krishan Yadav @GameYadav}

Contributors MH is the first author and was responsible for the study design, data collection, statistical analysis and writing of the manuscript. CH assisted with study design data collection and review of the manuscript. JJP, LM, MT, KA and KY provided methodological and statistical support in addition to manuscript review.

Funding This study was partially funded by a grant from the Department of Emergency Medicine, University of Ottawa.

Competing interests $\mathrm{MH}$ receives a salary as Hospital Donation Physician from Trillium Gift of Life Network, Ontario's organ donation organisation and JJP is supported by the Heart and Stroke Foundation of Ontario through a Mid-Career Award.

\section{Patient consent for publication Not applicable.}

Ethics approval This study was approved by the Ottawa Health Science Network Research Ethics Board (approval 20190178). All participants of the survey received an introductory letter stating that completion of the survey indicated consent to participate in the study.

Provenance and peer review Not commissioned; externally peer reviewed.

Data availability statement Data are available upon reasonable request. Requests for sharing of the data will be considered and reviewed by the study's steering committee. Requests can be made to Dr.Hickey.

Supplemental material This content has been supplied by the author(s). It has not been vetted by BMJ Publishing Group Limited (BMJ) and may not have been peer-reviewed. Any opinions or recommendations discussed are solely those of the author(s) and are not endorsed by BMJ. BMJ disclaims all liability and responsibility arising from any reliance placed on the content. Where the content includes any translated material, BMJ does not warrant the accuracy and reliability of the translations (including but not limited to local regulations, clinical guidelines, terminology, drug names and drug dosages), and is not responsible for any error and/or omissions arising from translation and adaptation or otherwise.

Open access This is an open access article distributed in accordance with the Creative Commons Attribution Non Commercial (CC BY-NC 4.0) license, which permits others to distribute, remix, adapt, build upon this work non-commercially, and license their derivative works on different terms, provided the original work is properly cited, appropriate credit is given, any changes made indicated, and the use is non-commercial. See: http://creativecommons.org/licenses/by-nc/4.0/.

\section{ORCID iDs}

Michael Hickey http://orcid.org/0000-0001-9674-0246

Monica Taljaard http://orcid.org/0000-0002-3978-8961

\section{REFERENCES}

1 Klabunde CN, Willis GB, McLeod CC, et al. Improving the quality of surveys of physicians and medical groups: a research agenda. Eval Health Prof 2012;35:477-506.

2 Cummings SM, Savitz LA, Konrad TR. Reported response rates to Mailed physician questionnaires. Health Serv Res 2001;35:1347-55.

3 Cho YI, Johnson TP, Vangeest JB. Enhancing surveys of health care professionals: a meta-analysis of techniques to improve response. Eval Health Prof 2013;36:382-407.

4 Brtnikova M, Crane LA, Allison MA, et al. A method for achieving high response rates in national surveys of U.S. primary care physicians. PLoS One 2018;13:e0202755.

5 Cook DA, Wittich CM, Daniels WL, et al. Incentive and reminder strategies to improve response rate for Internet-based physician surveys: a randomized experiment. $J$ Med Internet Res 2016;18:e244.

6 Abdulaziz K, Brehaut J, Taljaard M, et al. National survey of physicians to determine the effect of unconditional incentives on response rates of physician postal surveys. BMJ Open 2015;5:e007166.

7 Thorpe C, Ryan B, McLean SL, et al. How to obtain excellent response rates when surveying physicians. Fam Pract 2009;26:65-8.

8 VanGeest JB, Johnson TP, Welch VL. Methodologies for improving response rates in surveys of physicians: a systematic review. Eval Health Prof 2007;30:303-21.

9 Kellerman SE, Herold J. Physician response to surveys. A review of the literature. Am J Prev Med 2001;20:61-7.

10 McLeod CC, Klabunde CN, Willis GB, et al. Health care provider surveys in the United States, 2000-2010: a review. Eval Health Prof 2013;36:106-26.

11 Dillman DA. Mail and Internet surveys: the tailored design method. 2nd ed. Hoboken, N.J: Wiley, 2007.

12 Perry JJ, Losier JH, Stiell IG, et al. National survey of emergency physicians for transient ischemic attack (TIA) risk stratification consensus and appropriate treatment for a given level of risk. CJEM 2016;18:10-18.

13 Shiono PH, Klebanoff MA. The effect of two mailing strategies on the response to a survey of physicians. Am J Epidemiol 1991;134:539-42.

14 Dykema J, Stevenson J, Day B, et al. Effects of incentives and prenotification on response rates and costs in a national web survey of physicians. Eval Health Prof 2011;34:434-47.

15 Edwards PJ, Roberts I, Clarke MJ, et al. Methods to increase response to postal and electronic questionnaires. Cochrane Database Syst Rev 2009;3:MR000008.

16 Gattellari M, Zwar N, Worthington JM. No difference demonstrated between faxed or Mailed prenotification in promoting questionnaire response among family physicians: a randomized controlled trial. $J$ Clin Epidemiol 2012;65:544-52.

$17 \mathrm{Xie}$ Y, Ho SC. Prenotification had no additional effect on the response rate and survey quality: a randomized trial. $J$ Clin Epidemiol 2013;66:1422-6.

18 Fox RJ, Crask MR, Kim J. Mail survey response rate: a metaanalysis of selected techniques for inducing response. Public Opin $Q$ 1988;52:467-91. 